\title{
Violação de segrêdo
}

Basileu Garcia

\begin{abstract}
Sumário: 1 - Bem juridico das figuras delituosas. 2 - Divulgação do conteúdo de dojcumento particular ou correspondência confidencial. 3-O consentimento. 4 - Natureza do dano. 5-Segrêdo profissional. 6 - Conceito e titular do segrêdo. 7 - Sujeito ativo. 8 - Casos de inexistência do dever de sigilo. 9-Caráter necessário da revelação ou conhecimento. 10 Justa causa. 11 - Honorários médicos. 12 - Interêssse de terceiro e bem público. 13 - Aspectos do dolo e da responsabilidade objetiva. $14-0$ testemunho.
\end{abstract}

(*) 1 - Os delitos concernentes à violação de segrêdo estão capitulados entre os que ofendem a liberdade individual. Tem-se criticado essa forma de encarar o assunto, que não é só nossa, mas também de outros códigos penais. Aquêles que se batem pela colocação de tais delitos sob a rubrica "Dos crimes contra a liberdade individual" acham que a possibilidade da violação de segrêdo cria constrangimento para os cidadãos, perturbando as suas relações na vida social. Ao que Florban, ironicamente, obtempera: dessa forma, poder-se-ia também considerar como crime atentatório da liberdade individual o ato do vendeiro que furtasse no pêso, porque a possibilidade de ser lesado criaria certo constrangimento para o eventual comprador...

(*) Do curso realizado na Faculdade de Direito da Universidade de São Paulo. 
Não só Florian, como em geral os escritores franceses. Garraud, Garçon, Ghauveau e Hélie, sustentam que o crime de violação de segrêdo, particularmente o segrêdo profissional, não ofende, propriamente, a liberdade individual. A ofensa produzida é coletiva, uma of ensa a bem público, que é a confiança entre os cidadãos, a ser assegurada e protegida pelo Direito Penal. Argumenta-se especialmente com o sigilo profissional. O advogado que trái o seu cliente, violando o segrêdo colhido no desempenho dos seus encargos, o médico que, com a sua indiscrição, decepciona o enfêrmo que o procurou para lhe referir o segrêdo de uma enfermidade, não estão atentando contra a liberdade do cidadão e sim conculcando a fé dos seus misteres. Certas profissões não poderiam ser exercidas sem a cuidadosa observância de normas morais, entre as quais se inscreve o dever de sigilo.

2 - O art. 153 do Código Penal enuncia: "Divulgar alguém, sem justa causa, conteúdo de documento particular ou de correspondência confidencial, de que é destinatário ou detentor, e cuja divulgação possa produzir dano a outrem: Pena - detenção, de um a seis meses, ou multa, de trezentos mil réis a dois contos de réis". Procede-se mediante representação do ofendido. E o que preceitua o parágrafo único.

Seja frisada, em primeiro lugar, a conexidade entre o assunto dêsse dispositivo e o dos anteriores, pertinentes à inviolabilidade da correspondência. Quem se apossa de correspondência alheia quase sempre viola o respectivo segrêdo. E o faz também, via de regra, para utilizar-se do segrêdo, isto é, para divulgá-lo.

Assinala-se melhor essa analogia, ainda, considerandose que o texto ora em exame menciona expressamente a correspondência, além de aludir a documento particular: documento particular ou correspondência confidencial.

Por que "confidencial"? Quando é confidencial a correspondência? Muitas pessoas têm o hábito de escrever à margem da carta, transversalmente: "confidencial". Quan- 
do o signatário não o declara, a correspondência deixa de ser confidencial? Evidentemente, a lei não podia confiar só ao desejo do signatário considerar ou não confidencial a missiva. Acho imprópria essa palavra "confidencial". Parece-me que pode prestar-se a confusão. Não creio que haja sido objetivo do legislador dirigir a tutela decorrente dêsse texto exclusivamente ao caso em que a carta diga respeito a fatos de natureza íntima. A regra geral deve ser o sigilo da correspondência, quer se refira, quer não, a fatos intimos. Lembre-se que, amplamente, o texto constitucional assegura a inviolabilidade da correspondência.

Por outro lado, seria errôneo, a meu ver, restringir-se a tutela jurídica sob a influência do adjetivo "confidencial". porque a proteção penal instituída no mesmo dispositivo também alcança todo documento particular. Ora, uma carta que não fôsse estritamente confidencial equivaleria, no mínimo, a documento particular. Como tal, é suscetível da proteção a que se refere a lei.

Dir-se-á : o legislador não quer conceder a tutela penal em favor de cartas quanto às quais não haja interêsse algum de sigilo. Acontece, porém, que a lei, no final do dispositivo, apresenta esta cláusula: "cuja divulgação possa produzir dano a outrem". É o bastante para entender-se não haver crime na divulgação de cartas destituídas de importância, sem necessidade do duvidoso vocábulo "confidencial".

3 - Volvamos à questão do consentimento. Tenho admitido eficácia descriminante ao consentimento do remetente de uma carta que autoriza a sua interceptação por terceira pessoa, salvo hipótese de evidente dano. Mas é preciso não esquecer que, em relação a certas cartas, aquelas cuja divulgação, nos têrmos dêste artigo, possa produzir dano, não teria o remetente a faculdade de fazê-la violar, desde que, assim procedendo, o executor da violação tomasse conhecimento do conteúdo. Se a carta encerra um segrêdo, se contém informes sôbre fato cuja revelação produz dano 
ou pode produzí-lo, o signatário da missiva não é senhor de determinar o seu conhecimento por terceiros, porque ensejaria o crime de revelação de segrêdo. Então, embora fôsse inaplicável o art. 153 na parte que diz "correspondência confidencial de que é destinatário", pois o divulgador seria o remetente, poderia ser acusado do crime alegandose ter divulgado "correspondência confidencial de que é detentor", pois o remetente, com o auxílio de outrem, estaria detendo a carta.

O segrêdo contido numa carta, a informação que não deve ser divulgada, interessa ao remetente e ao destinatário. Se ambas as pessoas estiverem ligadas por um segrêdo, nenhuma delas poderá, sem justa causa (deve ser uma causa relevante), permitir que outra pessoa o conheça. Quem assim procedesse estaria cometendo o crime do art. 153.

4 - O dano de que se trata é o potencial. Bem compreensível é a expressão "possa produzir dano a outrem". Não se exige a efetividade do prejuizo. Basta a sua possibilidade. Pode ser patrimonial e moral. A lei não distingue.

E quanto à vítima dêsse dano, deve ser sempre um particular? É o que se tem querido inferir em face da expressão "a outrem". Se houver, porém, em algum caso, dano público, êsse dano não estaria protegido pela disposição que examinamos? No dano público há, necessariamente, e de forma implícita, o dano privado. Respondo que o dispositivo se aplica à hipótese do dano público.

Mas convém estabelecer uma distinção. A natureza pública do dano pode deslocar o procedimento para outro dispositivo da lei penal. No art. 325, o Código define o crime de violação de sigilo funcional, de que é agente o funcionário público, que também pode ser réu do crime previsto, em seguida, pelo art. 326 (violação do sigilo de proposta de concorrência). E o dec.-lei n. 4.766 , de $10^{\circ}$ de outubro de 1942, que, durante a última guerra, instituíu numerosas figuras delituosas em benefício da defesa nacio- 
nal, em vários preceitos cogitou da revelação de segredos, cominando penas severíssimas, mesmo a de morte. Êsse estatuto, de feitio excepcional, já não vigora.

5 - O segrêdo protegido penalmente pode ser de natureza profissional. Sôbre o assunto estabelece o art. 154: "Revelar alguém, sem justa causa, segrêdo, de que tem ciência em razão de função, ministério, ofício ou profissão, e cuja revelação possa produzir dano a outrem: Pena detenção, de três meses a um ano, ou multa, de um conto a dez contos de réis". Também a ação penal por êsse delito só pode instaurar-se mediante representação.

Ao passo que o segrêdo de que cogita o artigo precedente é sempre escrito, pois se concretiza em correspondência confidencial ou documento particular, o segrêdo a que alude o presente dispositivo pode ser transmitido por escrito ou oralmente, sendo mais comum essa segunda maneira de transmissão.

6 - Precisemos o que se deve entender por segrêdo. Não cabe na lei distinção: o segrêdo pode dizer respeito à honra, à saúde, aos bens, ao patrimônio, aos negócios, etc. À própria vaidade, sentimento humano muito respeitável. Nenhuma limitação existe. Não se observa restrição, também, quanto aos modos pelos quais pode o segrêdo chegar ao conhecimento do sujeito ativo, acusado de violá-lo. Poderá ter conhecimento do segrêdo diretamente, de viva voz, ou incidentemente, no exercício das funções que o põem em contato com o depositante. Casualmente, o segrêdo pode ser descoberto no exercício da profissão.

E não é preciso que o segrêdo se refira ao depositante. Pode dar-se que se relacione com outra pessoa, o que é uma conclusão interessante, porque concorre para solucionar-se, em certos casos, a dúvida quanto a saber a quem cabe a iniciativa da ação penal. Um pai chama determinado médico para atender à filha doente, que, para maior clareza do exemplo, suporemos ser maior. Se da assistência profissional prestada resultar depois, por leviandade ou maldade do 
facultativo, a revelação de segrêdo alusivo à moléstia, tanto se dirá ser sujeito passivo da infração o pai como a filha. Ambos podem ter a iniciativa do procedimento repressivo. mediante a representação legal.

Visto que a lei não diz o que seja segrêdo, para fixar o alcance da proteção penal, devemo-nos basear no significado usual da expressão. Por mais íntimo que seja um fato, não se poderá pretender que constitua segrêdo, se fôr notó1io. Às vêzes, são notórios fatos íntimos. Podemos conceituar o segrêdo como sendo o informe, referente a um acontecimento, que não deve, pela sua natureza ou por efeito de manifestação da vontade do depositante, ser transmitido a outras pessoas. Dar-se-á às vêzes que tem conhecimento do segrêdo um restrito número de pessoas, o que não será suficiente para considerar-se o fato como notório. Haverá então segrêdo passível de proteção penal.

7 - Muito importante, fundamental mesmo, na compreensão da figura delituosa acêrca do sigilo profissional, é a indagação de quem pode ser sujeito ativo do crime.

Três sistemas se conhecem, nas legislações. Em alguns códigos, a enumeração das pessoas que podem praticar tal crime é taxativa. Assim acontece no Código Penal alemão. Em outros estatutos, como o francês, a indicação é exemplificativa ou demonstrativa. O Código Penal francês faz referência ao médico, ao cirurgião, à parteira, e, numa fórmula largamente compreensiva, a outras pessoas que, pelo seu estado ou profissão, sejam vinculadas ao dever de guardar. o segrêdo que se lhes confiou. Note-se, para posterior exame, êste elemento: "que se lhes confiou". Um terceiro sistema, que é o do Código Penal italiano, adotado pelo nosso estatuto, prefere indicar as pessoas que podem ser sujeito ativo da infração através de uma fórmula genérica. Não se mencionam funções ou profissões. Fixá-las é tarefa a executar-se por inferência.

Não há, no nosso art. $154_{n}$ alusão a médicos, advogados, sacerdotes, parteiras, enfermeiros, enfermeiras. As pessoas que exercem tais profissões perpassam pelo nosso pensa- 
mento, a propósito da obrigação de guardar segrêdo profissional.

A lei não diz que o segrêdo deva ser confiado. Não seguiu o nosso Código, portanto, nesse passo, o modêlo francês. Basta que o sujeito ativo tenha ciência do segrêdo em razão da atividade que exerce. Não é preciso que alguém, declaradamente, deposite, ao conhecimento de outra pessoa, determinado segrêdo.

$\mathrm{O}$ texto, dessa forma, amplia um tanto a possibilidade de incriminação. Mas, por outro lado, restringe também. Porque é evidente que, se o suposto sujeito ativo tem conhecimento do fato secreto de outro modo que não em razão do exercício das suas atividades profissionais, não pratica o crime. O advogado tem o dever de sigilo profissional em relação ao cliente. Entretanto, se, após havê-lo defendido, é chamado ao pretório criminal para prestar depoimento que diga respeito ao cliente, e se o fato que lhe fôr perguntado, embora secreto, não the tenha chegado ao conhecimento em razão da sua função de advogado, nada impedirá que o narre. Não incorrerá na disposição punitiva que estamos examinando. Mas comete o crime o advogado se divulgar segrêdo que, conquanto não lhe tenha sido confiado pelo cliente, descobriu no exercício da sua atividade profissional.

A enumeração taxativa é perigosa. Por isso é que, naturalmente, o nosso Código se afastou dela. Com efeito, ao indicar, numa fórmula restrita, quais as pessoas que podem praticar o crime, corre o legislador o risco de exceptuar indevidamente pessoas que pratiquem atos merecedores da punição estabelecida.

8 - Entretanto, a fórmula adotada, se tem por um lado essa vantagem, também of erece inconvenientes, porque pode deixar o juiz criminal perplexo, quanto a saber se a certas manifestações da atividade humana se aplica o preceito penal proibitivo da violação do sigilo. Haverá, por exemplo, um sigilo profissional dos motoristas, dos carregadores, dos empregados domésticos? 
Certa vez, na França, em célebre processo, o processo Caillaux-Calmette, um empregado doméstico se esquivou de prestar o seu depoimento, invocando o sigilo profissional. Calmette havia sido assassinado pela sra. Caillaux, por instigação do marido. Importantíssima testemunha seria o criado do casal. Êle, contudo, recusou-se a depor.

De acôrdo com a nossa lei, o criado estaria isento de prestar o seu testemunho? Quem declarar que comete violação de sigilo profissional um criado que vá depor acêrca de atos dos patrões, ipso facto, o está isentando de depor. Não se pode obrigar quem quer que seja a praticar um crime. Muito menos o pode fazer a Justiça, constrangendo uma testemunha a agir criminosamente.

Outras hipóteses semelhantes podem ser propostas. Dá-se um crime dentro de um automóvel. Só o presenciou, além dos participantes, o chauffeur. Êle teve conhecimento do fato em razão do seu ofício. Incidirá na figura delitual em aprêco se prestar o seu depoimento? Poderá, comodamente, dizer ao juiz: "não deponho, porque a lei tolera que nã's deponha; manda-me mesmo não depor"? E se um carregador fôr chamado a prestar o seu depoimento acêrca das coisas que transportou, poderá dizer também: "não deponho em homenagem ao sigilo profissional dos carregadores"?

Pode afigurar-se que a posição de todos êsses trabalhadores esteja abrangida pelo preceito punitivo que examinamos. Não há dúvida de que as suas atividades representam o desempenho de um ofício, palavra empregada pela lei.

Mas estou certo de que ninguém admitiria a obrigatoriedade do sigilo profissional dessas pessoas. E qual seria o fundamento de tal solução jurídica?

9 - Para bem compreender o alcance do texto penal, cumpre atentar-se acuradamente nos objetivos sociais que o informam. Se bem que o delito esteja capitulado entre os of ensivos à liberdade individual, domina entre os fundamentos da incriminação, conforme se advertiu de início, a necessidade de proteger a confiança recíproca entre os cida- 
dãos, para lhes permitir recorrer, com segurança e tranquilidade, a misteres que outros exercem, e dos quais não poderiam de forma alguma servir-se, receando a infidelidade de quem, inevitavelmente, lhes recolherá as revelações. É preciso que todos saibamos que, ao procurar um médico, por exemplo, nos acercamos de pessoa que não nos vai trair. Aquêle que tem necessidade de um advogado, com o qual se aconselhe e que o proteja, deve estar convicto de que o defensor não o vai apontar depois como criminoso, em lugar de defendê-lo.

Mas não é a toda e qualquer profissão que se estende essa imperiosa necessidade de tutela da confiança pública. Quanto às profissões liberais, não há a menor dúvida de que a lei as tem em vista. Além delas, são abrangidas as funções que, pela sua especial natureza, se relacionam com a imprescindibilidade de auxílio material e moral ao sujeito passivo, colocando-o na obrigatória contingência de dar a conhecer fatos íntimos, em relato sem o qual não seria possível — ou não seria completo — o amparo que procura.

Assim, o sacerdote. Ainda que não houvesse, na Igreja Católica, o dogma sacerdotal da inviolabilidade da confissão, a natureza do ato é tal que todos compreendemos ser: inviolável — protegido penalmente — o segrêdo da confissão. Santo Agostinho dizia: "O que sei pela confisșão, eu o sei menos do que o que nunca soube". E o que dizemos do ministério sagrado do confessor é possível também estender à atividade do médico e do advogado, embora em grau algo menor de intensidade moral.

Reconheço que não estão expressas na lei as limitações que estabeleço pela fixação dos intuitos que devem guiá-la e que servem à sua exegese. Sob êsse aspecto, é clara a restrição do Código francês "segrêdo que se lhes confia", restrição que não se encontra no nosso Código. Protegido apenas o segrêdo confiado, não se alcançariam o motorista, o carregador, o criado, que ocasionalmente surpreendessem o segrêdo. Mas nenhum dêsses profissionais exerce ativida- 
des a que a vítima seja obrigada a recorrer exibindo os recessos da sua alma, ou de qualquer modo transmitindo fatos secretos. E êsse estado de dependência é que, essencialmente, explica a proteção penal do sigilo.

Para que haja o crime, é preciso, em suma, que tenha caráter necessário a revelação do segrêdo pelo interessado, ou o seu conhecimento pelo depositário, mesmo sem direta enunciação. Não seria possível ao depositante utilizar-sé dos serviços "daquele" profissional sem o envolver no segrêdo.

Com êsse critério, que é de toda procedência, admitiremos a existência do delito ainda relativamente a humildes profissionais. Suponha-se um ofício mecânico, o de serralheiro. O trabalhador é chamado a substituir a fechadura de um cofre. O dono do cofre não poderia, êle próprio, fazer o serviço, nem incumbir de o realizar um amigo qualquer. Depende do serralheiro. Êste permanece, em compensação, adstrito ao dever de segrêdo profissional.

Mas o motorista, por exemplo, que surpreende segrêdo de passageiros do seu automóvel, não o faz em caráter necessário. Não há, para êsses levianos indivíduos, nada que os obrigue a fazer relatos comprometedores dentro de um taxi.

10 - A lei diz que é possível desatender ao sigilo profissional mediante justa causa. Vamos focalizar algumas das hipóteses que excetuam a aplicação da pena.

Antes de mais nada, sempre que ocorrer um dever juridico de revelar o segrêdo, haverá justa causa. O médico não pratica ato punível quando, compelido por disposição dos regulamentos sanitários, denuncia uma enfermidade infectuosa, daquelas compreendidas em preceitos legais sôbre a higiene pública. Tem o dever jurídico de violar o segrêdo profissional. Se não o fizesse, cometeria o crime definido no art. 269 do Código Penal. Surge, portanto, em seu favor, justa causa. 
Ve modo geral, poderemos dizer que sempre que, consoante o entendimento predominante na moral social, se explicar honestamente a violação do sigilo, existirá justa causa, embora a atitude daquele que transmitiu o segrêdo não caiba, com precisão, em um dos textos das justificativas penais.

Pergunto, como exemplo: o médico tem o direito de comunicar à família de certa moça que o seu noivo, de quem está êle tratando, é portador de moléstia contagiosa? Poderá revelar a natureza do mal? A questão deve ser encarada de duas maneiras. Primeira, do ponto de vista estritamente jurídico. Do ponto de vista da ética profissional, cada médico resolverá por sí a questão. É matéria de fôro íntimo. Muitos dirão: "Eu violaria o segrêdo profissional". Outros: "Eu jamais violaria o segrêdo profissional; acho que é absoluto e não relativo". Encarada, entretanto, a questão pelo prisma estritamente jurídico, é evidente que nenhum juiz negaria, na hipótese, o reconhecimento da justa causa, se tivesse de apreciar a responsabilidade do médico submetido a tal imputação. Tudo leva a crer que declararia inexistente o crime, pela intercorrência de justa causa, que até se poderia entender representada pela justificativa do estado de necessidade. 0 problema jurídico, a êsse respeito, é muito mais simples do que o problema moral. Felizmente, porém, o problema moral não é nosso.

Médicos eminentes têm discutido a questão. AFRÂNio Peixoto estudou na sua Medicina Legal o tema do segrêdo médico, lembrando que o facultativo não tem o direito de ser nocivo. E sugere (sem o ânimo de o afirmar categoricamente) que, naquela hipótese, o médico deve violar ou quase violar o segrêdo profissional. A sua proposta é interessante. Imagina êsse caso e propõe que o médico, com intenção, responda à pessoa que o inquire: "Não posso violar o sigilo profissional". E logo em seguida reconhece que o interessado compreenderá. Mas, se compreende, é porque foi violado o sigilo profissional. O médico só não violaria o segrêdo se deixasse o interrogante sem conhecer absoluta- 
mente o seu pensamento. Se o médico se manifesta com escopo de não ser nocivo e com o intento, embora discreto, de fazer-se entendido, está violando o sigilo profissional.

11 - Estudam os escritores a questão de saber se pode o médico, que contende em juízo com um cliente para a cobrança de honorários, revelar o sigilo profissional, aludindo à moléstia de que foi ou é portador. Estaria o médico, que violasse segrêdo em tal situação, procedendo em defesa de um diréito seu. Essa defesa de direito constitui justa causa?

Encarando também tal hipótese, Afrânio PeIxoto não chega a opinar que inexista justa causa, mas prefere propor que o médico faça o sacrifício do seu direito aos honorários e não revele o segrêdo.

Os criminalistas, aos quais consultei, respondem que seria um caso de justa causa. Interessante, porém, é a posição em que se coloca, nesse problema, Lessona. Condiciona a situação jurídica do médico que assim agisse ao seu eventual êxito na ação cível, raciocinando dêste modo: se o médico viola o sigilo profissional, para demonstrar a natureza dos trabalhos que realizou em favor do cliente que não the quer pagar os honorários, poderá estar agindo, ou não, razoavelmente. Quem vai dizê-lo é o juiz do cível, ao conceder-lhe ou negar-lhe ganho de causa. Mas é muito combatido tal entendimento, e com toda procedência o criticam, porque o triunfo ou o fracasso de alguém numa demanda nem sempre depende de ter razão. Muitas vêzes o litigante está cheio de razão e não consegue demonstrá-la, porque lhe escasseiam os meios de prova. Seria, portanto, absurdo que se estabelecesse tal condição para admitir-se, ou não, a justa causa.

12 - Pergunta-se também se o consentimento tem poder liberatório do sigilo profissinal. A regra, que convém estabelecer, é que o consentimento exerce influência. Quando existe um segrêdo, através dêle está alguém ligado por um 
dever a outra pessoa. Se essa outra pessoa concorda em desprender o agente da obrigatoriedade do sigilo, desapareceo interêsse social da punição. Configura-se, portanto, justa causa.

Duas restrições, porém, cabe fazer. Não se deve admitir justa causa, em havendo consentimento, quando o segrêło não diga respeito ao depositante ou só a êle, e sim a outra pessoa. E também não se deve admitir justa causa quandor o segrêdo versa sôbre bem público. Então, não se compreende que o particular, que confiou o segrêdo, possa dispensar outrem da obrigação de guardá-lo.

13 - Pode suceder que alguém revele um segrêdo por estar embriagado. Não tendo consciência do seu ato, não procede com vontade criminosa. Deve-se-lhe admitir a inexistência de dolo, isentando-o de pena? É o que, à primeira vista, pode parecer.

Jamais, contudo, o estado de perturbação psíquica pelo álcool ou substâncias de efeitos análogos pode ser examinado, em relação a qualquer forma delituosa prevista no Código, sem se terem presentes os princípios da Parte Geral. A embriaguez, embora completa, - voluntária ou culposa diz a lei, não exclui a responsabilidade. Se não a exclui, mesmo que a pessoa esteja completamente embriagada, entende-se que age com dolo. Na verdade, não age. Nós o sabemos. Mas estabelece-se, legalmente, que age. A lei cria aí um verdadeiro caso de culpabilidade objetiva, uma responsabilidade sem culpabilidade, a qual é presumida. Só quando a embriaguez completa seja originária de caso fortuito ou fôrça maior é que, de acôrdo com os mencionados princípios, estará excluída a responsabilidade. Em todos os demais casos, embora alcoolizado completamente, o agente é responsável.

Dir-se-á que a conclusão é chocante e contrária à realidade. Mas é o que está na lei, e já tivemos ocasião de comentar por que a lei é assim rigorosa. Sendo o alcoolismo um grande mal, quís o legislador estabelecer normas. 
tendentes a impedir a alegação de embriaguez como escusa ou simples atenuante. Em certo caso, a embriaguez é mesmo agravante: quando preordenada, procurada propositadamente para a prática do crime. Assim, se um advogado, por exemplo, se embriaga com o escopo de encorajar-se a trair um cliente, referindo o seu segrêdo, terá exacerbada a sua responsabilidade, mesmo que se comprove estar completamente alcoolizado.

$\mathrm{E}$, ainda quando originária de caso fortuito ou fôrça maior, a embriaguez não impede a responsabilidade criminal do agente, se fôr incompleta.

Casos haverá em que alguém revele o segrêdo, dormindo. Então, evidentemente, não existirá o dolo. Há pessoas que têm o mau hábito de falar durante o sono.

ìs vêzes, alguém revela um segrêdo profissional porque é indiscreto e imprudente. Quase somos induzidos a admitir a figura culposa de violação de segrêdo profissional. Mas as leis não cogitam da hipótese. $\mathrm{Na}$ indiscrição sempre é possível perceber-se um mínimo de intuito de revelar o segrêdo. Nunca será alguém tão abstrato que não saiba o que está dizendo, ao referir fatos importantes. Existe certa dose apreciável de elemento subjetivo, que será o dolo.

14 - Uma das questões de maior interêsse prático, relacionadas com êste assunto, é a do testemunho. Pergunta-se qual deve ser a atitude de alguém que se acha ligado a um segrêdo profissional e que é chamado a prestar o seu depoimento.

A testemunha está obriyada ao sigilo profissional, de acôrdo com o texto que examinamos. Deve declarar-se vinculada pelo segrêdo e abster-se de depor. As leis protegem essa atitude. $O$ art. 144 do Código Civil diz: "Ninguem pode ser obrigado a depor de fatos, a cujo respeito, por estado ou profissão, deva guardar segrêdo". Também o Código de Processo Civil, no art. 241, adverte que a testemunha pode recusar-se a depor sôbre fatos cujo relato importe violação do sigilo profissional. E o Código de Pro- 
cesso Penal, no art. 207, declara serem proibidas de depor as pessoas que, em razão de função, ministério, ofício ou profissão, devam guardar segrêdo, salvo se, desobrigadas pela parte interessada, quiserem dar o seu testemunho.

Como se vê, o Código de Processo Penal admite expressamente que o consentimento do interessado desfaça a obrigação de sigilo. Mas, para se tornar possível o depoimento, essa condição deve estar conjugada à de que o depositário do segrêdo delibere dar o seu testemunho. Apesar da aquiescência do depositante, pode acontecer que o depositário sinta escrúpulos, que a lei respeita. Trata-se de assunto sigiloso, em que entrar nas indagações sôbre as reservas mentais do depositário equivaleria, por vêzes, a penetrar no próprio segrêdo. Este pode ser atinente a outras pessoas, além daquela que, arrogando-se a qualidade de interessado, dispense o sigilo. E ninguém melhor do que o depositário pode conhecer os reflexos malignos que teria a sua revelação.

Entretanto, por ser fiel à custódia do segrêdo recebido, não terá a testemunha de recusar-se, invariavelmente, a depor. Acontecerá em certas ocasiões que o segrêdo concirna a ligeiro pormenor dos fatos de que tem conhecimento. Não deve, então, sonegar o seu auxílio à Justiça. Procurará distinguir, do que lhe é permitido referir, o que lhe é interdito. Cabe-lhe dizer, a certo passo do depoimento: "A essa pergunta não posso responder, porque a informação redundaria em violação do sigilo profissional". $E$ se tal escusa puder servir a interpretações que, indiretamente, conduzam a desvendar-se o segrêdo, será conveniente que a testemunha declare ignorar a circunstância perguntada, evasiva em que não seria lícito vislumbrar qualquer propósito anti-jurídico de faltar à verdade.

$\mathrm{E}$ se a testemunha, ante as perguntas que as partes ou o juiz lhe dirijam, fizer uma declaração que infrinja o sigilo profissional, pratica o delito ou haverá justa causa? Inclino-me à solução de que ocorre justa causa. A pessoa, afinal, está sendo legitimamente provocada. Pode não ter. 
no momento, toda a lucidez e presença de espirito e ministrar um informe em consequência dessa provocação. $\mathbf{t}$ de se admitir a justa causa.

A possibilidade de justa causa em semelhante conjuntura é ainda mais nitidamente perceptível através do Código de Processo Civil. O seu art. 241 tolera, em princípio, que a testemunha queira conservar determinados segredos. Alude o dispositivo não só ao segrêdo profissional, como a questões sôbre as quais os informes importariam desonra para o depoente ou determinadas pessoas que lhe são ligadas, ou a perigo de dano patrimonial imediato. Mas a recusa a depor, prossegue a lei, deve ser emitida por escrito, antes da audiência, cabendo ao juiz aceitá-la ou não. Se não a acolher, pode compelir a testemunha a depor, sob pena de prisão disciplinar até cinco dias, além de multa. Conquanto não seja de esperar que o magistrado obrigue a depor quem invoca, com plausiveis razões, segrêdo profissional, não é de todo inadmissível que isso suceda. $O$ constrangimento instituiria justa causa em favor do depoente.

Como se verifica, não são inteiramente harmônicos, sôbre tão relevante matéria, o Código de Processo Penal e o de Processo Civil. O primeiro respeita, com firmeza, a deliberação da testemunha que invoca segrêdo profissional. O segundo sujeita-a a exame do juiz.

Convém, todavia, distinguir. Pode acontecer que o depoente se sinta propenso a violar intencionalmente o sigilo profissional e esteja à procura de uma oportunidade para fazê-lo, acobertando-se num simulacro de justa causa. Assim, o juiz criminal que mais tarde julgasse a atitude do revelador do sigilo profissional teria de dar muita atenção ao ânimo do agente.

Quando Chauveau e HÉlie, na sua magnífica Teoria do Código Penal, escreveram, no século passado, acêrca do segrêdo profissional, observaram que no seu país só um penalista, LEGRAVEREND, era contrário a admitir-se que alguém se escusasse a depor alegando a obrigação do sigilo. Ar- 
gumentava esse escritor que a sociedade toda necessita e reclama o esclarecimento dos crimes e que, assim, não seria justo que alguém, sobrepondo-se ao imperativo que domina a coletividade, se prevalecesse do sigilo profissional resguardando um criminoso.

Responderam, entretanto, com acêrto, Chauveau e Hélie, que o interêsse na apuração dos delitos não é o único que existe. O Estado tem, de igual modo, interêsse em proteger as relações entre os cidadãos fundadas na confiança recíproca, em fortalecer a solidariedade humana, em velar pelo cumprimento dos deveres morais. Exigindo o depoimento, o poder público estaria insuflando a traição $e$ perturbando gravemente o exercício de profissões para as quais o segrêdo é condição de existência. 